BMJ Open

Sport \&

Exercise

Medicine

\title{
Injury surveillance in elite field hockey: a pilot study of three different recording techniques
}

\author{
Anna Levi, ${ }^{1}$ Till-Martin Theilen, ${ }^{1}$ Udo Rolle (D) ${ }^{2}$
}

To cite: Levi A, Theilen T-M, Rolle U. Injury surveillance in elite field hockey: a pilot study of three different recording techniques. BMJ Open Sport \& Exercise Medicine 2020;0: e000908. doi:10.1136/ bmjsem-2020-000908

Accepted 24 October 2020
Check for updates

(C) Author(s) (or their employer(s)) 2020. Re-use permitted under CC BY-NC. No commercial re-use. See rights and permissions. Published by BMJ.

${ }^{1}$ Department of Paediatric Surgery and Paediatric Urology, University Hospital of the GoetheUniversity, Frankfurt/M, Germany ${ }^{2}$ Department of Paediatric Surgery and Paediatric Urology, Hospital of the Goethe University Frankfurt, Frankfurt Am Main, Germany

Correspondence to Udo Rolle; udo.rolle@kgu.de

\section{ABSTRACT}

Objective In field hockey, injuries are assessed by various recording techniques leading to a heterogenic collection of poorly comparable injury data.

Methods Injury data were prospectively collected at the 2016 Men's Hockey Junior World Cup using the match injury reports (MIRs), video injury clips provided by the Fédération Internationale de Hockey, and daily medical reports (DMRs). A pilot study comparing injury type, mechanism, location on the field, injured body part and overall injury incidence among the different injury recording techniques was performed.

Results MIRs and video injury clips were completely available for analysis. DMRs were returned from 11 out of 16 teams (69\%). In total, MIRs yielded 28 , video analysis 36 , and DMRs 56 injuries. Overall injury rate varied between 24.8 and 57.9 injuries per 1000 player match hours. The majority of injuries affected the lower limbs by all three methods (41.7-61.2\%) and were mainly caused by having been hit by the ball $(20.4-50 \%)$ or stick (11.1-28.6\%). Reports of concussions during competition were incoherent between MIR (2 cases) and DMR (no cases). The DMR was the only method to record overuse injuries (16.1\%), injuries in training (12.5\%), and time-loss injuries of one or two days $(12.5 \%)$ or of three or more days $(14.3 \%)$.

Conclusion Injury data vary substantially between the MIR, DMR and injury video recording technique. Each recording technique revealed specific strengths and limitations. To further advance injury research in field hockey, the strengths of each recording technique should be brought together for a synergistic injury assessment model.

\section{INTRODUCTION}

Field hockey is a game of great speed and athleticism. Due to the fast-moving ball, physical interaction of the players, the use of a stick, and playing on a mainly blunt surface, injuries are common. Data on field hockey injuries have accumulated over the last decade in youth tournaments, ${ }^{1}$ college field hockey, ${ }^{2} 3$ junior world cups, ${ }^{4} 5$ and professional field hockey. ${ }^{6-8}$ Although, all these data contribute to better understand the nature of field hockey injuries, they lack comparability due to the use of different recording techniques.
Summary box

What are the new findings?

- MIR, DMR and video injury recording in field hockey detect a different set of injuries.

- The DMR was the only method to record overuse injuries $(16.1 \%)$, injuries in training $(12.5 \%)$, and time-loss injuries of one or two days $(12.5 \%)$ or of three or more days (14.3\%).

- Reports of concussions during competition were incoherent between medical officials at the sideline ( 2 cases) and the daily medical reports by the teams' medical staff (no cases).

- Video analysis detects almost twice as much head injuries than injury recording methods from the sideline (MIR, DMR).

The most widely used injury recording technique is the registration of injuries by medical officials on injury report forms at the pitch site (match injury report, MIR). This technique is mandatory during all official field hockey tournaments of the Fédération Internationale de Hockey (FIH). In many competitions, national leagues and/or youth tournaments, injury data consist of reports from the teams' medical staff (physicians, therapists or athletic trainers) or of telephone-assisted interviews of athletes. ${ }^{9}$ A new injury recording technique in sports is the utilisation of video sequences of injuries. Recently, we published our first results on video injury assessment in field hockey, and we proposed video analysis as a valuable complementary tool in field hockey injury assessment. $^{10}$

All injury recording techniques focus on different aspects of the injury. MIR focusses on technical aspects in assessing time, location, type, mechanism, and affected body part of an injury. Injury assessment by the teams' medical personnel mainly focuses on the well-being of the athletes. Formal aspects such as time and location of an injury on the playing field may be less important in this injury assessment. However, the teams' 
medical reports are of great value since they can provide information on after-match injuries triggered by an incident during a game, injuries during training, or overuse injuries. Video analysis may well contribute to a better understanding of injuries in field hockey. For example, slow motion and repetitive play of an injury scene gives detailed information of injury mechanisms. An injury by a fast-flying ball can sometimes not be realised by a person at the field side but can be captured on camera.

Overall aims in injury research are identification of valid injuries, consistency in data collection and comparability of data. ${ }^{11}$ These aims are impossible to reach by using only a single observation technique. Therefore, this prospective cohort study aimed to analyse three different injury recording techniques at an FIH youth elite field hockey tournament (Men's Junior World Cup 2016).

\section{METHODS}

\section{Subjects and study period}

The data were prospectively collected at the 2016 Men's Hockey Junior World Cup in Lucknow, India. The tournament was carried out by the Fédération Internationale de Hockey (FIH). For data acquisition, three different injury recording techniques were used independently: MIRs from FIH officials at the field site, injury video clips provided by the FIH, and DMRs from the team's medical staff.

\section{Injury assessment techniques}

The MIRs were completed by the FIH Medical Officer. An injury was defined as a new musculoskeletal symptom or head injury that led to time stoppage by the umpire. All of these injuries were acute injuries during competition. We evaluated the injury recordings in relation to time, location and mechanism, type of injury and affected body parts (table 1).

The video evaluation was conducted with the use of video clips of all matches showing all injuries with a time stoppage by the umpire. These video clips were provided by the FIH. There is an established procedure to review, select and produce video clips of injuries of specific tournaments within the FIH. Evaluation of these videos clips was performed according to a special designed protocol. The video evaluation included only acute match injuries leading to time stoppage by the umpire. Later sequelae, that is, concussions could not be diagnosed by video analysis as objective clinical assessment was not possible by video analysis (table 1 ).

All participating teams were asked to record injuries of their athletes on the standardised DMR form. The DMR was designed according to the existing team medical reports used by the International Olympic Committee (IOC). ${ }^{12}$ The form included information on injury mechanism, injury type and injured body part.

The DMR included acute injuries (injuries requiring time stoppage by the umpire, medical attention injuries by the team's medical team), overuse injuries and injuries that became apparent sometime after a match or training. Overuse injuries were defined as injuries that are caused by repetitive trauma. Furthermore, DMR also provided information on the length of absence from training or competition (in days; time-loss injuries) (table 1).

All report forms (MIR, DMR) and video clips were assessed individually by all three investigators of this study. Table 1 gives an overview of differences in acquisition of data among the injury assessment techniques used.

\section{Statistical analysis}

The registered injuries were standardised as injuries per match within a 95\% CI and as injuries per 1000 player match hours $(\mathrm{PMH})$. Total PMH were calculated as follows: number of players (11 active athletes per team on the field of play, 22 in total) multiplied by the total number of games (44) and the match duration (70 $\mathrm{min})$ divided by $60 \mathrm{~min}$. All injuries during matches including

Table 1 Overview on differences in acquisition of data among different injury assessment techniques in field hockey

\begin{tabular}{|c|c|c|c|c|c|c|c|c|c|c|}
\hline \multirow[b]{2}{*}{ Method } & \multirow[b]{2}{*}{ Revisor } & \multicolumn{3}{|c|}{ Basic data } & \multicolumn{3}{|c|}{ Data on the injury } & \multirow[b]{2}{*}{$\begin{array}{l}\text { Overuse } \\
\text { injury }\end{array}$} & \multirow[b]{2}{*}{$\begin{array}{l}\text { Injury } \\
\text { during } \\
\text { training }\end{array}$} & \multirow[b]{2}{*}{$\begin{array}{l}\text { Absence } \\
\text { days }\end{array}$} \\
\hline & & $\begin{array}{l}\text { Match } \\
\text { number }\end{array}$ & $\begin{array}{l}\text { Time of } \\
\text { play }\end{array}$ & $\begin{array}{l}\text { Location } \\
\text { on pitch }\end{array}$ & $\begin{array}{l}\text { Mechanism } \\
\text { of injury }\end{array}$ & $\begin{array}{l}\text { Type of } \\
\text { injury }\end{array}$ & $\begin{array}{l}\text { Injured } \\
\text { body } \\
\text { part }\end{array}$ & & & \\
\hline $\begin{array}{l}\text { Match } \\
\text { Injury } \\
\text { report }\end{array}$ & $\begin{array}{l}\text { FIH } \\
\text { medical } \\
\text { official }\end{array}$ & $\checkmark$ & $\checkmark$ & $\checkmark$ & $\checkmark$ & $\checkmark$ & $\checkmark$ & - & - & - \\
\hline $\begin{array}{l}\text { Video } \\
\text { evaluation }\end{array}$ & $\begin{array}{l}\text { FIH } \\
\text { medical } \\
\text { official }\end{array}$ & $\checkmark$ & $\checkmark$ & $\checkmark$ & $\checkmark$ & $\checkmark$ & $\checkmark$ & - & - & - \\
\hline $\begin{array}{l}\text { Daily } \\
\text { Medical } \\
\text { Report }\end{array}$ & $\begin{array}{l}\text { Team's } \\
\text { medical } \\
\text { staff }\end{array}$ & $\checkmark$ & $\checkmark$ & - & $\checkmark$ & $\checkmark$ & $\checkmark$ & $\checkmark$ & $\checkmark$ & $\checkmark$ \\
\hline
\end{tabular}

$\mathrm{FIH}$, Fédération Internationale de Hockey. 
overuse injuries were included in this analysis. Acute and overuse injuries during training were analysed separately.

\section{Ethical approval}

The ethics committee of the Goethe-University of Frankfurt/Main approved the study (number 134/17).

\section{RESULTS}

\section{Overall number of injuries}

There were 16 teams playing 44 matches during the Junior Hockey World Cup 2016. All injury report forms and the injury video footage of all 44 matches were available and assessed. Eleven out of sixteen teams (69\%) returned a complete documentation of the DMR. Accordingly, only 33 matches included in the analysis of the DMR.

All three injury recording methods revealed different numbers of injuries. MIR yielded 28 and the video footage 36 injuries during the matches. DMR documented 56 injuries in total of which 47 were recorded during a match as a result of an acute injury and time stoppage.

In addition, DMRs displayed two injuries during the matches as a result of overuse. These injuries did not lead to time stoppage or attention by official medical staff at the field site. The DMRs also listed seven injuries during training (table 2).

\section{Match-associated injuries}

We compared all three injury recording methods by standardising the injury numbers to the number of injuries per match and 1000 player match hours. For accurate comparison among the three methods, injuries during training recorded by the DMR were omitted in this analysis. With 49 injuries, DMR revealed the most injuries with an average of 1,48 (CI 1.07 to 1.90) injuries per match and 57.9 injuries per 1000 player match hours (table 3).

\section{Injury characteristics}

Overuse injuries during matches were included in the analysis. Acute and overuse injuries during training were analysed separately.

\section{Time of an injury during the match}

All three methods reported more injuries during the second half of the match (MIR: $15(53.5 \%)$; video: $23(63.9 \%)$; DMR: $21(42.9 \%))$. However, one injury of the MIR and eight injuries of the DMR records were not allocated to any playing time (table 4 ).

\section{Injury location on the pitch}

The injury location on the pitch was only assessed by MIR and video evaluation, reporting most of the injuries either

Table 2 Total number of injuries recorded by three different recording methods during the Junior Hockey World Cup 2016

\begin{tabular}{|c|c|c|c|c|c|}
\hline \multirow[b]{2}{*}{$\begin{array}{l}\text { Recording } \\
\text { method }\end{array}$} & \multicolumn{2}{|c|}{ Injuries (n) during the match } & \multicolumn{2}{|c|}{ Injuries $(n)$ during training } & \multirow[b]{2}{*}{$\begin{array}{l}\text { Total Injuries }(n) \text { during the } \\
\text { tournament }\end{array}$} \\
\hline & $\begin{array}{l}\text { Acute } \\
\text { injuries }\end{array}$ & $\begin{array}{l}\text { Overuse } \\
\text { injuries }\end{array}$ & $\begin{array}{l}\text { Acute } \\
\text { injuries }\end{array}$ & $\begin{array}{l}\text { Overuse } \\
\text { injuries }\end{array}$ & \\
\hline MIR & 28 & - & - & & 28 \\
\hline Video & 36 & - & - & & 36 \\
\hline $\mathrm{DMR}^{*}$ & 47 & 2 & 4 & 3 & 56 \\
\hline
\end{tabular}

*11 out of 16 teams returned the DMR forms.

DMR, Daily Medical Report; MIR, Match Injury Report.

Table 3 Total and average number of injuries per match and injuries per 1000 player match hours recorded by three different recording methods during the Junior Hockey World Cup 2016

\begin{tabular}{llllll}
\hline $\begin{array}{l}\text { Recording } \\
\text { method }\end{array}$ & $\begin{array}{l}\text { Number of } \\
\text { matches }\end{array}$ & $\begin{array}{l}\text { Total player } \\
\text { match hours* }\end{array}$ & $\begin{array}{l}\text { Injuries (n) recorded } \\
\text { during all matches }\end{array}$ & $\begin{array}{l}\text { Average Injuries (n) } \\
\text { per match } \mathbf{( C I )}\end{array}$ & $\begin{array}{l}\text { Injuries per 1000 } \\
\text { player match hours }\end{array}$ \\
\hline $\begin{array}{l}\text { MIR } \\
\text { Video }\end{array}$ & 44 & 1129 & 28 & $0.64(0.33-0.94)$ & 24.8 \\
$\begin{array}{l}\text { DMR†, } \\
\begin{array}{l}\text { w overuse } \\
\text { injuries }\end{array}\end{array}$ & 34 & 1129 & 36 & $0.82(0.52-1.11)$ & 31.9 \\
$\begin{array}{l}\text { w/o } \\
\text { overuse } \\
\text { injuries }\end{array}$ & 33 & 847 & 49 & $1.48(1.07-1.90)$ & 57.9 \\
\hline
\end{tabular}

${ }^{*}$ Total player match hours=number of games $\times 70$ min per game $\times 22$ players per game/60 min, Cl=95\% Cl, MIR=Match Injury Report, DMR=Daily Medical Report.

$\dagger 11$ out of 16 teams returned the DMR.

$\ddagger$ Without 7 injuries during training, w/o, Without; $w$, With.

$\mathrm{FIH}$, Fédération Internationale de Hockey. 
Table 4 Injury characteristics of injuries during the Junior Hockey World Cup 2016 assessed by 3 different recording methods

\begin{tabular}{|c|c|c|c|c|}
\hline \multirow{2}{*}{ Number of injuries by } & & \multicolumn{3}{|c|}{ Recording methods } \\
\hline & & \multirow{2}{*}{$\begin{array}{l}\text { MIR (\%) } \\
(\mathbf{n}=\mathbf{2 8}) \\
12(42.9)\end{array}$} & \multirow{2}{*}{$\begin{array}{l}\begin{array}{l}\text { Video }(\%) \\
(\mathbf{n}=36)\end{array} \\
13(36.1)\end{array}$} & \multirow{2}{*}{$\begin{array}{l}\begin{array}{l}\text { DMR (\%) } \\
(n=49)\end{array} \\
20(40.8)\end{array}$} \\
\hline Time point during the match & 1st half & & & \\
\hline & 2nd half & $15(53.5)$ & $23(63.9)$ & $21(42.9)$ \\
\hline & Unknown & $1(3.6)$ & $0(0.0)$ & $8(16.3)$ \\
\hline \multirow[t]{4}{*}{ Location on the pitch } & Circle & 9 (32.2) & 19 (52.7) & - \\
\hline & 25 yard-line & $6(21.4)$ & $5(13.9)$ & - \\
\hline & Midfield & 11 (39.3) & $12(33.4)$ & - \\
\hline & Unknown & $2(7.1)$ & $0(0.0)$ & - \\
\hline \multirow[t]{8}{*}{ Injury mechanism } & Hit by ball & $9(32.1)$ & $18(50.0)$ & $10(20.4)$ \\
\hline & Hit by stick & $8(28.6)$ & $4(11.1)$ & $14(28.6)$ \\
\hline & Player contact & $4(14.3)$ & $6(16.7)$ & $6(12.2)$ \\
\hline & Surface contact & $0(0.0)$ & $0(0.0)$ & $7(14.3)$ \\
\hline & Tripping & $3(10.7)$ & $6(16.7)$ & $7(14.3)$ \\
\hline & Cramps & $1(3.6)$ & $2(5.5)$ & $3(6.1)$ \\
\hline & Overuse & - & - & $2(4.1)$ \\
\hline & Unknown & $3(10.7)$ & $0(0.0)$ & $0(0.0)$ \\
\hline \multirow[t]{9}{*}{ Injury type } & Contusion & $13(46.4)$ & $26(72.3)$ & $18(36.7)$ \\
\hline & Distorsion & $3(10.7)$ & $6(16.7)$ & $10(20.4)$ \\
\hline & Laceration & $3(10.7)$ & $2(5.5)$ & $6(12.2)$ \\
\hline & Abrasion & $0(0.0)$ & $0(0.0)$ & $7(14.3)$ \\
\hline & Concussion & $2(7.2)$ & - & $0(0.0)$ \\
\hline & Cramps & $1(3.5)$ & $2(5.5)$ & $3(6.25)$ \\
\hline & Knee bursitis & - & - & $1(2.1)$ \\
\hline & Bruise & - & - & $3(6.1)$ \\
\hline & Unknown & $6(21.5)$ & $0(0.0)$ & $0(0.0)$ \\
\hline \multirow[t]{5}{*}{ Injured body part } & Head/face & $5(17.9)$ & $13(36.2)$ & $8(16.3)$ \\
\hline & Upper limb & $0(0.0)$ & $3(8.3)$ & $11(22.5)$ \\
\hline & Lower limb & $13(46.4)$ & $15(41.7)$ & $30(61.2)$ \\
\hline & Trunk & $2(7.1)$ & $4(11.1)$ & $0(0.0)$ \\
\hline & Unknown & $8(28.6)$ & $1(2.7)$ & $0(0.0)$ \\
\hline
\end{tabular}

DMR, Daily Medical Report; MIR, Match Injury Report.

in the circle (MIR: 9 (32.2\%); video: $19(52.7 \%))$ or the midfield (MIR: 11 (39.3\%; video: $12(33.4 \%)$ ). In both methods, less injuries occurred at the 25yrd zone (MIR: 6 $(21.4 \%)$; video: $5(13.9 \%))$. In two cases $(7.1 \%)$, the MIR did not note the injury location (table 4 ).

\section{Injury mechanism}

Being hit by the ball was the predominant injury mechanism in all recordings (MIR: 9 (32.1\%); video: 18 (50.0\%); DMR: $10(20.4 \%)$ ), followed by being hit with the stick, collision with another player and tripping. Three injuries $(10.7 \%)$ of the MIR did not mention the injury mechanism (table 4).

\section{Type of injury}

In all three injury assessments, contusion was the main type of injury (MIR: 13 (46.4\%); video: 26 (72.3\%); DMR: $18(36.7 \%))$, followed by distortions (MIR: $3(10.7 \%)$; video: $6(16.7 \%)$; DMR: $10(20.4 \%))$ or lacerations (MIR: 3 (10.7\%); DMR: 6 (12.2\%)). In six MIR documentations $(21.5 \%)$, the injury type was not noted (table 4 ).

During the tournament, three concussions were observed: two during the match and one during training sessions. The two match injuries reported by MIR were as a result of being hit with a stick or ball (table 4). One concussion was a result of a collision between two players during training and was recorded by DMR.

\section{Injured body parts}

Most of the injuries affected the lower limb (MIR: 13 (46.4\%); video: 15 (41.7\%); DMR: $30(61.2 \%))$. In the evaluation of the DMR, the upper limb was the second most affected body part (11 (22.5\%)), whereas MIR and video evaluation showed head/face injuries as the second most injured body site (MIR: 5 (17.9\%); video: 13 
$(36.2 \%))$. In the MIR and video evaluation data on eight injuries and one injury, respectively, did not reveal the injured body part (table 4).

\section{Overuse injuries}

DMR reported two injuries during the match $(4.3 \% ; 2 / 47$ match injuries; one foot distorsion and one knee bursitis) and three injuries during training $(43.6 \% ; 3 / 7$ training injuries; one knee distorsion, one fasciitis of the foot and one foot fatigue fracture) as a result of overuse.

\section{Injuries during training}

$12.5 \%$ (7/56 injuries) of all DMR recorded injuries occurred in training. Four injuries were acute injuries caused by a hit with the ball (finger contusion and arm contusion), tripping (ankle distorsion) and collision with another player (concussion). The other three injuries were overuse injuries, as mentioned above.

\section{Length of absence after an injury}

Seven injuries $(12.5 \%)$ from a total of 56 injuries reported by the DMR led to an absence of 1 or 2 days, and eight injuries $(14.3 \%)$ led to an absence of 3 or more days. The majority of absence days resulted after an injury during the match (table 5).

\section{DISCUSSION}

This is the first study to analyse three different injury recording methods (injury recording at the field side by FIH medical officials, retrospective video analysis and reports by the teams' medical staff) at a single field hockey tournament.

\section{Overall injury data by recording technique}

The most striking observation was the difference in the overall injury numbers ranging from 24.8 to 57.9 injuries per 1000 player match hours (PMH) among the three recording techniques. This difference might be due to the fact that each recording technique focusses on the registration of different subsets of injuries. ${ }^{11} 1314$ The acquisition of injuries only when the umpire stops the time clock for a new musculoskeletal complaint, as in the MIR and video technique, can be considered as a 'narrow' recording technique resulting in fewer injuries being identified. The additional registration of medical attention and overuse injuries, as in the case in the DMR of our study, encompasses a wider range of injuries

Table 5 Number of absence days after an injury as reported in daily medical reports by the team's medical staff

\begin{tabular}{llll}
\hline & \multicolumn{3}{l}{ Absence days } \\
\cline { 2 - 4 } Injuries $(\mathrm{n})$ & None (\%) & $\mathbf{1 - 2}(\%)$ & $\mathbf{> 3}(\%)$ \\
\hline All injuries $(\mathrm{n}=56)$ & $\mathbf{4 1}(\mathbf{7 3 . 2})$ & $\mathbf{7 ( 1 2 . 5 )}$ & $\mathbf{8 ( 1 4 . 3 )}$ \\
$\begin{array}{l}\text { - Injuries during the match } \\
\text { - Injuries during training } \\
\quad \text { sessions }\end{array}$ & $4(90.2)$ & $6(85.7)$ & $6(75.0)$ \\
\hline
\end{tabular}

('broad' recording technique), leading to higher injury numbers. ${ }^{1115}$

The variation of the injury incidence by different recording techniques is reflected by the reported range of data in the literature. The reported $1000 \mathrm{PMH}$ injury incidence in men`s field hockey reveals a range between 12.3 injuries/1000 PMH (Dutch elite hockey players; questionnaire on health problems answered by the player), 47 injuries/1000 PMH (Olympic Games 2004, team physician injury report form), 48.3/1000 PMH for men (professional international field hockey tournaments, match injury report forms from medical officials), and 86 injuries/1000 PMH in boys (international elite youth field hockey tournaments, match injury report forms from medical officials). ${ }^{181617}$

A comprehensive injury base has not been built up due to the heterogeneity of recording methods in youth and adult field hockey. ${ }^{9}$ Our data from a single field hockey tournament clearly show that the currently available injury assessment methods reveal different injury numbers. Therefore, defining a standardised injury recording procedure in field hockey should be defined.

\section{Injury characteristics by recording technique}

All injury assessment methods showed that most of the injuries occurred during the second half of the game, which has been shown before in other studies. ${ }^{1}{ }^{10}$ The circle has been shown to be the main location for injuries, as revealed in previous studies. ${ }^{1810}$ The MIR, however, registered most injuries in the midfield, which has not yet been shown in other studies.

One of the most important and challenging aspects of injury research is the correct recording of the injury mechanism. ${ }^{11}{ }^{15}$ Interestingly, in the here presented data of the video analysis, a hit by a ball was the reason for an injury in $50 \%$ of cases. This incidence was much higher compared to the recordings of the other two methods. It is suggestible, that a person registering injuries at the sideline might not be able to correctly state whether an injury was caused by a hit of a stick or a (deflected) ball. In our experience, this situation is sometimes even difficult to evaluate by video. In video cases, however, slow motion and close-up views will usually disclose the body part and mechanism of injury.

All three recording methods documented contusions as the most frequent injury. It stands out that the video analysis demonstrated that the most common injuries were contusions $(72 \%)$ but did not reveal injuries as abrasion or bruises. This finding might have an obvious reason as the video analysis of injuries only reveals the acute status. A developing haematoma, abrasion, or any other injury sequela, such as a concussion, can only be examined by medical personnel on the pitch. DMR recording technique is therefore the most valuable assessment technique in the case of evaluating injury types.

The lower limb is the most affected site in previously published studies referring to injured body parts in field hockey. ${ }^{81618}$ This was also shown by the three recording 
techniques in the here presented study. By video analysis, $36 \%$ of the injuries affected the head and face as the second most injured body part. This percentage was twice as high as in the recorded numbers by the two other methods. As stated above, it might have been difficult to see which body part was injured. Video analysis and physical examination by the teams' medical staff may best document the injured body part correctly. It is important to note that the MIR had a very high number of unknown injured body parts (29\%), hinting at a weakness of this recording technique.

\section{Concussions}

Special attention has to be directed to the assessment of concussion. A consensus group of seven different sports has lately defined video signs for concussion. ${ }^{19}$ In this paper, however, we excluded video analysis as a tool to diagnose concussions. We believe those clinical symptoms and physical findings at the field site are still the most reliable signs to diagnose a concussion. In our analysis, two concussions were documented by the MIR during competition. The DMR classified these two head injuries as head contusion and not as concussions. The medical staff of a team has the best position to define the severity of a head injury. Their medical attention comes the closest to the athletes. They have the position for follow-up as concussion symptoms can evolve over time and become apparent later during or after the match.

\section{Overuse injuries}

Overuse injuries have not yet been assessed comprehensively in field hockey. We found one report of overuse injuries in Dutch elite field hockey stating a prevalence of $14 \%$ by self-assessing questionnaires of the players. ${ }^{17}$ In our data, $16.1 \%$ (9/56 injuries) were defined as overuse.

\section{Injuries in training}

Using the DMR enabled us to trace injuries that occurred in training sessions. We found that $12.5 \%$ of all injuries occurred in training. The number of training hours were not documented and therefore injuries per 1000 player training hours could not be calculated. However, we can conclude that training injuries exist and that they consist of the same injury types as match injuries (eg, contusion, distorsion, concussion). Almost half of all injuries in training were overuse injuries, meaning injuries without a direct causative event.

\section{Limitations}

It was not possible to overlay and cross-check all injuries of the three injury recording methods, because the recording of the match time of an injury differed among the methods. In addition, the player numbers were deliberately not noted (anonymous data sampling) making it impossible to correctly assign one injury to all three recording methods.

Another limitation was the incomplete data in some categories. Especially, in the MIR incomplete data were frequent in recording of injury types $(21.5 \%)$, injury mechanism $(10.7 \%)$, and injury location $(7.1 \%)$. The incompleteness of data in medical report forms is a known problem, as exemplified in other sports, such as in football. ${ }^{20}$ We have made the same observation in professional field hockey. ${ }^{8}$

\section{CONCLUSIONS}

None of the three analysed injury assessment tools resulted in a comprehensive data collection. This does not allow for valid conclusions and injury prevention advices. Therefore, uniform injury definition, recording method, and analysis will be necessary to achieve consistent injury recording. Other team sports have already established consensus about injury definition and data collection procedures, such as football and rugby. ${ }^{21} 22$

All here presented injury recording techniques have assets and drawbacks. To further advance injury research in field hockey, the strengths of the here analysed recording techniques should be brought together for a synergistic injury assessment (table 6). A group of (official) independent superordinate 'injury experts' should be assigned to master this logistic task. In praxis, each single injury documented by one method should be

\begin{tabular}{|c|c|c|}
\hline $\begin{array}{l}\text { Recording } \\
\text { technique }\end{array}$ & $\begin{array}{l}\text { Advantages in } \\
\text { assessing - }\end{array}$ & Reason \\
\hline MIR & - Basic injury data & $\begin{array}{l}\text { Official personnel } \\
\text { at the field side } \\
\text { Official personnel } \\
\text { of the FIH }\end{array}$ \\
\hline Video & $\begin{array}{l}\text { Injury } \\
\text { mechanism } \\
-\quad \text { Injured body part }\end{array}$ & $\begin{array}{l}\text { Replay } \\
\text { Slow motion } \\
\text { Close-up view } \\
\text { from different } \\
\text { angles }\end{array}$ \\
\hline DMR & $\begin{array}{l}\text { Injury type } \\
\text { (concussion for } \\
\text { example) } \\
\text { Injured body part } \\
\text { Injuries without } \\
\text { time stoppage of } \\
\text { the umpire } \\
\text { Overuse injuries } \\
\text { Absence days } \\
\text { Recording of } \\
\text { exact medical } \\
\text { diagnosis, for } \\
\text { example, } \\
\text { fracture (X-ray), } \\
\text { concussion } \\
\text { (symptoms might } \\
\text { become } \\
\text { apparent after } \\
\text { the match) }\end{array}$ & $\begin{array}{l}\text { Focuses on the } \\
\text { well-being of the } \\
\text { athlete } \\
\text { Direct medical } \\
\text { treatment of the } \\
\text { injured player on } \\
\text { the field } \\
\text { Medical } \\
\text { observation of the } \\
\text { player after } \\
\text { matches } \\
\text { Access to } \\
\text { diagnostic results }\end{array}$ \\
\hline
\end{tabular}

DMR, Daily Medical Report; FIH, Fédération Internationale de Hockey; MIR, Match Injury Report. 
counter checked by the other methods. Strengths of one method will make up for weaknesses of the other methods, for example, slow-motion video assessment to detect the injured body part of a fast moving, deflected ball or physical examination by the team's medical personnel for a clinical diagnosis of a concussion. Surely, this synergistic injury assessment will be time consuming, labour- and cost-intensive. In reward, however, it could consolidate and promote the efforts to implemented effective injury prevention and health protection of (young) hockey players.

Acknowledgements The authors wish to thank all teams and their medical staff for their participation in this study.

Contributors AL performed the study, evaluated the data, performed statistics and drafted the manuscript; $\Pi T$ evaluated the data, performed statistics and revised the manuscript; UR designed the study and revised the manuscript.

Funding The authors have not declared a specific grant for this research from any funding agency in the public, commercial or not-for-profit sectors.

Competing interests None declared.

Provenance and peer review Not commissioned; externally peer reviewed.

Data availability statement Data are available upon reasonable request.

Open access This is an open access article distributed in accordance with the Creative Commons Attribution Non Commercial (CC BY-NC 4.0) license, which permits others to distribute, remix, adapt, build upon this work non-commercially, and license their derivative works on different terms, provided the original work is properly cited, appropriate credit is given, any changes made indicated, and the use is non-commercial. See: http://creativecommons.org/licenses/by-nc/4.0/.

ORCID iD

Udo Rolle http://orcid.org/0000-0002-1268-6092

\section{REFERENCES}

1 Furlong LM, Rolle U. Injury incidence in elite youth field hockey players at the 2016 European championships. PLoS One 2018;13:e0201834.

2 Dick R, Hootman JM, Agel J, et al. Descriptive epidemiology of collegiate women's field hockey injuries: national collegiate athletic association injury surveillance system, 1988-1989 through 2002-2003. $J$ Athl Train 2007;42:211-20.

3 Gardner EC. Head, face, and eye injuries in collegiate women's field hockey. Am J Sports Med 2015;43:2027-34.
4 Mukherjee S. Head and face injuries during the men's field hockey junior world cup 2009. Am J Sports Med 2012;40:686-90.

5 Mukherjee S. Traumatic upper limb injuries during the men's field hockey Junior World Cup 2009. Res Sports Med 2013;21:318-29.

6 Murtaugh K. Injury patterns among female field hockey players. Med Sci Sports Exerc 2001;33:201-7.

7 Murtaugh K. Field hockey injuries. Curr Sports Med Rep 2009;8:267-72.

8 Theilen TM, Mueller-Eising W, Wefers Bettink P, et al. Injury data of major international field hockey tournaments. Br J Sports Med 2016;50:657-60.

9 Barboza SD, Joseph C, Nauta J, et al. Injuries in field hockey players: a systematic review. Sports Med 2018;48:849-66.

10 Theilen TM, Mueller-Eising W, Bettink PW, et al. Video analysis of acute injuries in elite field hockey. Clin J Sport Med 2020.

11 Clarsen B, Bahr R. Matching the choice of injury/illness definition to study setting, purpose and design: one size does not fit all! Br J Sports Med 2014;48:510-2.

12 Junge A, Engebretsen L, Alonso JM, et al. Injury surveillance in multi-sport events: the International Olympic Committee approach. $\mathrm{Br}$ J Sports Med 2008;42:413-21.

13 Hodgson L, Gissane C, Gabbett TJ, et al. For debate: consensus injury definitions in team sports should focus on encompassing all injuries. Clin J Sport Med 2007;17:188-91.

14 Orchard J, Hoskins W. For debate: consensus injury definitions in team sports should focus on missed playing time. Clin J Sport Med 2007; 17:192-6.

15 Bahr R, Clarsen B, Derman W, et al. International Olympic Committee consensus statement: methods for recording and reporting of epidemiological data on injury and illness in sport 2020 (including STROBE extension for sport injury and illness surveillance (STROBE-SIIS)). Br J Sports Med 2020;54:372-89.

16 Junge A, Langevoort G, Pipe A, et al. Injuries in team sport tournaments during the 2004 Olympic Games. Am J Sports Med 2006;34:565-76.

17 Delfino Barboza S, Nauta J, van der Pols MJ, et al. Injuries in Dutch elite field hockey players: a prospective cohort study. Scand J Med Sci Sports 2018;28:1708-14.

18 Engebretsen L, Soligard T, Steffen K, et al. Sports injuries and illnesses during the London Summer Olympic Games 2012. Br J Sports Med 2013;47:407-14.

19 Davis GA, Makdissi M, Bloomfield P, et al. International consensus definitions of video signs of concussion in professional sports. $\mathrm{Br}$ J Sports Med 2019;53:1264-7.

20 Bjorneboe J, Florenes TW, Bahr R, et al. Injury surveillance in male professional football; is medical staff reporting complete and accurate? Scand J Med Sci Sports 2011;21:713-20.

21 Fuller CW, Molloy MG, Bagate C, et al. Consensus statement on injury definitions and data collection procedures for studies of injuries in rugby union. Br J Sports Med 2007;41:328-31.

22 Fuller CW, Ekstrand J, Junge A, et al. Consensus statement on injury definitions and data collection procedures in studies of football (soccer) injuries. Br J Sports Med 2006;40:193-201. 